\title{
Profile of Hand Compartment Syndrome in Dr. Hasan Sadikin General Hospital, West Java, 2008-2012
}

\author{
Kajendaran Manogaran, ${ }^{1}$ Nucki Nursjamsi Hidajat, ${ }^{2}$ Arifin Soenggono ${ }^{3}$ \\ ${ }^{1}$ Faculty of Medicine Universitas Padjadjaran, ${ }^{2}$ Department of Orthopaedics \& Traumatology \\ Faculty of Medicine Universitas Padjadjaran/Dr. Hasan Sadikin General Hospital Bandung, \\ ${ }^{3}$ Department of Anatomy and Cell Biology, Faculty of Medicine Universitas Padjadjaran
}

\begin{abstract}
Background: Compartment syndrome is a serious disorder caused by elevated pressure in a muscle compartment that can progress to muscle and nerve damage. This disorder can happen to anyone but more frequently in young adults. The occurrence frequency of hand compartment syndrome is relatively low. The aim of this study is to identify the profile of compartment syndrome in patients hand

Methods: A descriptive study was perfomed to 15 cases that were collected from medical records from 2008-2012, in Dr. Hasan Sadikin General Hospital. The profile of the case consisted of age, sex, symptoms and signs, etiology, facsiotomy schedule after admission, length of stay and patient's outcome. The collected data were presented using tables.

Results: The study showed that 12 out of 15 cases were males and 7 out of 15 cases were 20-39 years old patients. The common clinical findings were swelling, pain, limited range of motion and normal sensibility. The faciotomy procedure was conducted 1 day after the admission with length of stay more than 1 week. The patients condition were improved after operation.

Conclusions: Hand compartment syndrome is a rare case, mostly affects younger adults and male. Most of the symptoms and signs are swelling, limitation of movement, pain in the location area with normal sensibility. The faciotomy procedure is conducted 1 day after admission. The length of stay is more than 1 week with an improved outcome. [AMJ.2015;2(4):497-501]
\end{abstract}

Keywords: Compartment syndrome, hand, swelling

\section{Introduction}

Compartment syndrome is a serious medical disorder caused by elevated pressure in a muscle compartment that can progress to muscle and nerve damage. This condition is influenced by external and internal force or injury that increases the intracompartmental pressure. ${ }^{1,2}$ The most common findings for compartment syndrome are pain, tenderness and swelling. Others include paraesthesia, pallor, paralysis and pulselessness. ${ }^{3,4}$ Apart from clinical signs and symptoms, the important diagnostic method is by measuring intracompartmental pressure. ${ }^{5}$ The choice of treatment normally done for patient with compartment syndrome is through a surgical method. The essential step of patient treatment with compartment syndrome is by performing fasciotomy procedure to release the pressure within involved compartment. ${ }^{6,7}$

From the previous study in 2011 by Duckworth and Mcqueen $^{5}$, it was noted that the occurrence of hand compartment syndrome is less frequent. The involvement of upper extremities is less common comparing to lower extremities. The yearly occurrence of acute compartment syndrome is 3.1 per 100.000 population with the ratio in male to female is $10: 1 .^{5}$ Even though it is a rare syndrome, this condition can lead to a serious complication and affect the patient's quality of life and daily living activities. The aim of the study is to identify the profile of patients with hand compartment syndrome which is a common orthopedic disorder.

Correspondence: Kajendaran Manogaran, Faculty of Medicine, Universitas Padjadjaran, Jalan Raya Bandung-Sumedang Km.21, Jatinangor, Sumedang, Indonesia, Email: kajendaran@yahoo.com 


\section{Methods}

A descriptive study was performed to 15 medical records of patients with hand compartment syndrome during 2008-2012 in Dr. Hasan Sadikin General Hospital. The data collection was carried out from August 2013 to November 2013. The profile of the patients consisted of age and sex. Futhermore, 7 out of 15 cases which were patients between 20-39 years old, were analyzed according to diagnosis criteria, etiology, facsiotomy schedule after admission, length of stay and patient's outcome.

The collected data was presented in tables for each variable to represent the hand profile of compartment syndrome. The study was approved by the Health Research Ethics Committee of Dr. Hasan Sadikin General Hospital.

\section{Results}

From 2008 until 2012, there were only 15 cases of hand compartment syndrome. Most of the cases were affected by male patients who were 20-39 years old.

Seven cases from 20-39 years old patients had been selected to identify other variables than age and sex.

Most of the patients had the same symptoms and signs. Those were swelling, limited in range of motion, yet there was one patient who did not feel pain.

From seven cases, most of the patients had an injury before and only one case was occur because of a tight bandage. Fasciotomy was performed one day after the admission, but there were still cases performed more than 2 day after the admission. Furthermore, the
Table 1 Distribution of Patients According to Age and Sex

\begin{tabular}{|c|c|c|c|}
\hline \multirow{2}{*}{$\begin{array}{c}\text { Age } \\
\text { (years) }\end{array}$} & \multicolumn{2}{|c|}{ Sex } & \multirow{2}{*}{$\begin{array}{c}\text { Total } \\
\text { (n) }\end{array}$} \\
\hline & Male (n) & Female (n) & \\
\hline$<20$ & 2 & 3 & 5 \\
\hline $20-39$ & 7 & 0 & 7 \\
\hline $40-59$ & 2 & 0 & 2 \\
\hline$>60$ & 1 & 0 & 1 \\
\hline Total & 12 & 3 & 15 \\
\hline
\end{tabular}

length of stay between patients varied from 6 to 74 days. Most of the patients outcomes were improved.

\section{Discussion}

The incidence of hand compartment syndrome is very low.5 In this study, only 15 cases found during 2008-2012. Most of the cases were affected to 20-39 years old patients. The possible reason is adults normally more engaged in daily activities, sports activities, and more exposed to outer environment compare to other age group population. This finding is supported by epidemiology research done by Duckworth and Mcqueen. ${ }^{5}$ It is important to note that hand is important part of our body with many influential functions. Gambrel explains that in a certain situation such as in sports or working environment, it requires overuse of hand in completing a task or activity. This can lead to higher chances of damage or injury to the hand. ${ }^{8}$

This study also shows that males are more affected by this syndrome than female. Previous study by Duckworth and Mcqueen ${ }^{5}$

Table 2 Diagnostic Criteria of Compartment Syndrome of The Hand

\begin{tabular}{lccccccc}
\hline Patient & Swelling & Pain & ROM* & Wound & Sensibility & $\begin{array}{c}\text { Other } \\
\text { disorders }\end{array}$ & ICP** \\
\hline 1 & Yes & Yes & Limited & Yes & Normal & Burn injury & Not done \\
2 & Yes & Yes & Limited & Yes & Normal & Leg injury & Not done \\
3 & Yes & No & Limited & Yes & No & Burn injury & Not done \\
4 & Yes & Yes & Limited & No & Normal & None & Not done \\
5 & Yes & Yes & Limited & No & Normal & None & Not done \\
6 & Yes & Yes & Limited & Yes & Normal & Leg injury & Not done \\
7 & Yes & Yes & Limited & Yes & No & None & Not done \\
\hline
\end{tabular}

Note: *ROM, range of motion, ${ }^{* *} \mathrm{ICP}$, intracompartmental pressure 
Table 3 Profile of Patients with Compartment Syndrome of The Hand

\begin{tabular}{lcccccc}
\hline Patient & $\begin{array}{c}\text { Age } \\
\text { (years) }\end{array}$ & Sex & Etiology & $\begin{array}{c}\text { Fasciotomy } \\
\text { (days after } \\
\text { admission) }\end{array}$ & $\begin{array}{c}\text { Length of } \\
\text { hospital } \\
\text { stay } \\
\text { (days) }\end{array}$ & Outcome \\
\hline 1 & 30 & Male & Burn injury & 7 & 42 & Improved \\
2 & 33 & Male & Accident & 1 & 36 & Improved \\
3 & 24 & Male & Burn injury & 15 & 74 & Complicated \\
4 & 20 & Male & Tight bandage & 1 & 11 & Improved \\
5 & 20 & Male & Fall & 3 & 39 & Improved \\
6 & 37 & Male & Accident & 1 & 29 & Improved \\
7 & 28 & Male & Crush injury & 1 & 6 & Complicated \\
\hline
\end{tabular}

statistically presented that mostly males were usually the main sufferer in compartment syndrome cases with ratio of 10:1 to female.

In this study, most of the patients have the history of injury before the occurrence of hand compartment syndrome. A previous study by Mabvuure et al. ${ }^{6}$ supported this findings. The study also mentioned that trauma commonly resulted in compartment syndrome. Traumatic accident and working hazard injury can prolong and progress to range of mild to severe hand injury as explained by Chow et al. ${ }^{9}$ All the causal factors stated can explain the pathophysiology of the compartment syndrome as all the causes can either increase the compartment volume or decrease the compartment size. ${ }^{10}$ This condition increases intracompartmental pressure.

Diagnostic criteria of compartment syndrome of the hand are studied. It includes the clinical findings that are different from person to person and depend on the severity of disorder. Results show common findings in all seven patients are swelling and limited range of motion. Presence of swelling or pain sensation will limit the movement of hand and fingers. Any deep or severe injury can cause damage to nerve and muscle, thus it progress into more chronic compartment syndrome. This condition as explained in previous articles will affect the normal functioning of the hand. Other findings in the patients include pain, loss of sensibility, and wound. As already written in the literature before, the classic clinical findings are 5P (pain, paraesthesia, pallor, paralysis, pulselessness). In certain condition not all the findings will present, so it is important to study the characteristic of the syndrome before diagnosing the patient. ${ }^{3,5,10}$
Measuring intracompartmental pressure is also an important diagnostic criteria for compartment syndrome as explained in study by Duckworth and Mcqueen. ${ }^{5}$ Based on study, all seven cases did not use the measurement of intracompartment pressure, probably due to the emergency and serious disorder need a fast and prompt management. Chandraprakasam and Kumar ${ }^{4}$ also state that clinical findings are the most important part in diagnosing compartment syndrome and intracompartment pressure measurement can be done as the confirmation of disorder.,10

Fasciotomy is an invasive procedure to treat the compartment syndrome. The objective of this procedure is to open the involved tissue compartments to relieve the pressure before irreversible tissue damage occur. ${ }^{6}$ Olson and Glasgow suggested that if there was clinical indications of acute compartment syndrome more than 8 hours and with absence in muscular and neurologic function, then amputation procedure must be conducted. ${ }^{7,11}$ In this study, not all of the patients underwent fasciotomy promptly. As explained by Ebraheim et al. $^{12}$, the compartment syndrome should be diagnosed and treated as fast as possible. This is important to prevent progression of syndrome and prevent complications. ${ }^{3}$ Patient can also develop a contracture of chronic stage in the compartment syndrome that is clinically characterized by fibrosis and a shortening of muscle because of inadequate vascularization.

Systemic complications include renal insufficiency is caused by rhabdomyolysis and myoglobulinaemia as the results of high intracompartmental pressure. ${ }^{13}$ It is important for patient to immediately consult to a doctor after an injury or trauma and to accept the 
management plan provided for them. The other two cases require a longer time because it has other accompanying serious disorder (Table 2).

From seven cases, the length of stay in hospital varies, most patients have been treated for a longer time in hospital. The length of hospitalization is essential to check for presence of any complications after the operative procedure example such as local complications that are post-operative wound infection and deeper infection involving soft tissue or bones that could lead to amputation, nerve damage or other disorder.,11 Once the patient has recovered from the surgery without complications, then they can be sent home. The length of hospitalization also depends on the severity of the injury. Multiple site injuries require more long term management. This applies to a patient that has been treated for a longer period.

This study also represents the management outcome of hand compartment syndrome shown that most patients, five in number of cases discharged with an improved condition after management. Most of these patients were managed well and fast to prevent any complication and the injury not to severe enough to cause irreversible disorder. From the study, two patient's outcomes are complicated into nerve damage and contracture. It is because of the late admission after injury causing irreversible damage. According to study by Szatmary et al. ${ }^{13}$ with a quick and proper treatment and management, the risks in developing complication can be avoided. This is important as it can preserve the normal hand functions and patient's quality of life

The limitation of the study is the low number of data obtained regarding this disease due to a rare disease factor. Secondly, incompleteness of the information in medical records are also proved to be a barrier in the study. It is recommended that the necessary information should be completed in all medical records to ease further study of the disease. Although compartment syndrome of the hand is considered as a rare disorder, it is important for the healthcare workers to develop skills and techniques for the diagnosis and management of the patients with this condition. Public needs to be educated about the risk of having compartment syndrome. They should try avoiding the risk and causal factors of compartment syndrome to prevent the occurrence of this condition that could lead to many complications if it is untreated. They also should be educated about the overuse syndrome of hand especially for workers or athletes that often use repetitive and forceful movement of the hand. If they find any abnormality in hand, it will be better to immediately consult to a doctor to treat their conditions.

It can be concluded that hand compartment syndrome is a rare case, mostly affected younger adults and male. Most of the symptoms and signs are swelling, limitation of movement, pain in the location area with normal sensibility. The procedure to treat this condition is fasciotomy. Futhermore, the length of stay is more than 1 week with an improved outcome.

\section{References}

1. Schubert AG. Exertional compartment syndrome: review of the literature and proposed rehabilitation guidelines following surgical release. Int J Sports Phys Ther. 2011;6(2):126-41

2. Sung CY, Chung RK, Ra YS, Lee HS, Lee GY. Impending compartment syndrome of the forearm and hand after a pressurized infusion in a patient under general anesthesia. Korean J Anesthesiol. 2011;60(1):60-3.

3. Cole A, Pavlou V, Warwick D. Injuries of the shoulder, upper arm and elbow. In: Solomon L, Warwick D, Nayagam S. Apley's system of orthopaedics and fractures. 9th ed. Boca Raton: CRC Press; 2010, p.711-4

4. Chandraprakasam T, Kumar RA. Acute compartment syndrome of forearm and hand. Indian J Plast Surg. 2011;44(2):212-8.

5. Duckworth AD, Mcqueen MM. Focus on diagnosis of acute compartment syndrome. The Journal of Bone \& Joint Surgery. 2011. [cited 2013 March 12]. Available from: http://www.boneandjoint. org.uk/sites/default/files /Focus $\% 20$ On $\% 20$ Diagnosis $\% 20$ of $\% 20$ acute $\% 20$ compartment $\% 20$ syndrome.pdf

6. Mabvuure NT, Malahias $M$, Hindocha S, Khan W, Juma A. Acute compartment syndrome of the limbs: current concepts and management. Open Orthop J. 2012;6:535-43.

7. Green DP. General principles. In: Wolf SW, Pederson WC, Hotchkiss RN, Kozin SH. Green's operative hand surgery. 6th ed. Philadelphia: Elsevier Churchill Livingstone; 2011

8. Gambrell CR. Overuse syndrome and the unilateral upper limb amputee: 
consequences and prevention. J Prosthet Orthot. 2008;20(3):126-32.

9. Chow CY, Lee H, Lau J, Yu IT-S. Transient risk factors for acute traumatic hand injuries: a case-crossover study in Hong Kong. Occup Environ Med. 2007;64(1):47-52.

10. Taylor RM, Sullivan MP, Mehta S. Acute compartment syndrome: obtaining diagnosis, providing treatment, and minimizing medicolegal risk. Curr Rev Musculoskelet Med. 2012;5(3):206-13.

11. Canale ST, Beaty JH, editors. Campbell's operative ortopaedics.
11 th ed.
Philadelphia: Mosby Elsevier; 2008

12. Ebraheim NA, Abdelgawad AA, Ebraheim MA, Alla SR. Bedside fasciotomy u n d e r local anesthesia for acute compartment syndrome: a feasible and reliable procedure in selected cases. J Orthop Traumatol. 2012;13(3):153-7.

13. Szatmary P, Erdös J, Constantin D, Humenberger M, Vécsei V, Hajdu S. Cute compartment syndrome in children: a case series in 24 patients and review of the literature. Int Orthop. 2010;35(4):569-75. 